\title{
“O SOL DA LIBERDADE PURA AQUI RELUZ CONTÍNUO": A CONSTRUÇÃO DA IMPRENSA LUSÓFONA NA INGLATERRA (1808-1822)'
}

\author{
Luís Francisco Munaro*
}

\begin{abstract}
Resumo: O estudo da imprensa periódica luso-brasileira na cidade de Londres entre 1808 e 1822 revela a necessidade sentida pelos elementos luso-brasileiros de instaurarem um dizer-suporte para significar o Reino Português diante do público inglês. $O$ confronto com os jornais ingleses permitiu a solidificação e mesmo a definição de linhas profissionais para o funcionamento da imprensa em Portugal e Brasil. Além disso, forneceu dados importantes para pensar o papel dos intelectuais exilados para o fomento de uma esfera pública literária em língua portuguesa cujas bases de sustentação estavam protegidas pela constitucionalidade britânica.
\end{abstract}

Palavras-chave: história do jornalismo português; esfera pública burguesa; The Morning Chronicle; Correio Braziliense; Hipólito da Costa.

\begin{abstract}
The study of the Luso-brazilian periodical press in the city of London between 1808 and 1822 reveals the need felt by Luso-Brazilian elements to introduce one "support of telling" for Brazil before the English public. The comparison with the well-established English press allowed to solidify and even to define professional lines for the operation of the press in Portugal and Brazil. It also provided important data to think about the role of the press in exile for the promotion of a literary public sphere in Portuguese, whose support bases were established precisely on foreign soil protected by British constitutional history.
\end{abstract}

Keywords: history of portuguese journalism; bourgeois public sphere; The Morning Chronicle; Correio Braziliense; Hipólito da Costa.

\footnotetext{
* Doutor em História pela Universidade Federal Fluminense (UFF). Professor da Universidade Federal de Roraima (UFRR) - Boa Vista, Roraima, Brasil. E-mail: <luismunaro@yahoo.com.br>.

${ }^{1}$ Um esboço desse artigo foi apresentado no GP Teorias do Jornalismo do XXXVI Congresso Brasileiro de Ciências da Comunicação (Manaus - 2013).
} 
O jornalismo é uma atividade fundamental para a configuração de práticas sociais modernas. Assim como formas modernas de urbanidade e conduta são profundamente afetadas pelo discurso dos jornais. Conforme a vida se voltava para o espaço público no início do século XVIII, aumentava a necessidade de dados precisos sobre o espaço e o tempo, de forma que o círculo de interdependências urbano pudesse se tornar cada vez mais eficaz. Os jornais, pelo tempo a que aludiam e pelo esforço de sociabilidade urbana de que faziam parte, ajudavam a conferir precisão ao calendário e passavam a adquirir um papel cada vez maior na estruturação do cotidiano do homem moderno. Como descreve Benedict Anderson, bastava a data no alto da página dos jornais para assegurar aos leitores a passagem dos dias, sintonizando todos dentro de uma mesma narrativa cujo desfecho era a realização nacional (ANDERSON, 1989).

Segundo Jürgen Habermas, a consolidação do jornalismo estava vinculada à redação regular de epístolas que forneceram uma autonomia cada vez maior para o redator diante do seu público leitor (HABERMAS, 2003: 35). Estas cartas dirigidas regularmente assumiram a representação dos afetos e necessidades do leitor transformado em correspondente imbuído do espírito liberal de entendimento. ${ }^{2} \mathrm{O}$ jornalismo epistolar, ao contrário da Gazeta de coloração oficial, começava a se aproximar do seu público a partir do pressuposto de que ele constituía um grupo ligado por interesses privados semelhantes. Isso começava a acontecer mais nitidamente no início do século XVIII, em Londres, quando Daniel Defoe, gênio criativo considerado também um dos precursores do ensaísmo jornalístico, lançou entre 1704 e 1713

\footnotetext{
${ }^{2}$ A partir disso, o autor acrescenta que "A esfera pública burguesa pode ser entendida inicialmente como a esfera das pessoas privadas reunidas em um público; elas reivindicam esta esfera pública regulamentada pela autoridade, mas diretamente contra a própria autoridade, a fim de discutir com ela as leis gerais da troca na esfera fundamentalmente privada, mas publicamente relevante, as leis do intercâmbio de mercadorias e do trabalho social" (HABERMAS, 2003: 42).
} 
o periódico Weekly Review. À medida que anexava as cartas de seus leitores, Daniel Defoe também buscava detectar os seus gostos, ajudando a configurar uma esfera íntima de reflexões, independentes de qualquer autoridade externa à consciência individual. Iniciativas voltadas para o público doméstico já começavam a tocar em preocupações que remetiam à construção e organização do foro íntimo, lentamente convertido em foro privado. A expressão muito utilizada pelos jornalistas portugueses, "tribunal da opinião pública", concernia ao grupo de pessoas privadas unidas em torno da representação de seus interesses.

A ideia de fórum representa com relativa clareza a pretensão do jornalismo. No caso do jornalismo luso-brasileiro, a possibilidade de realizar um fórum em língua portuguesa está aberta aos portugueses no início da migração de 1807, quando o Marechal francês Junot invadiu Portugal. Os portugueses deram origem em Londres a uma profícua e movimentada comunidade de exilados políticos, que explorou ao máximo as possibilidades oferecidas pela liberdade de divulgação intelectual - inexistente em Portugal até a Revolução Liberal do Porto, em 1820. Os esquemas mentais do reformismo pombalino, que caracterizavam o que havia de mais moderno em Portugal, encontraram em Londres a imprensa diária e a esfera pública inglesa em pleno processo de ebulição. Nesse sentido, o que este texto busca perceber são os diálogos escritos e os contatos e atritos intelectuais movidos pelos portugueses emigrados, derivados, segundo eles, de uma má avaliação que a imprensa inglesa fazia de Portugal e do Brasil.

Em sua busca crescente por representatividade política, e como eco da comunidade de comerciantes exilados em Londres e no Brasil, a mentalidade lusófona foi responsável pela publicação de um amplo número de jornais, considerados aqui como um promissor fórum de doutrinas políticas. Estes jornais surgiram e se multiplicaram ao redor dos princípios iluministas esboçados por Hipólito da Costa e foram lentamente trabalhados para caberem dentro das especificidades luso-brasileiras. Dentre estes jornais cuja menção é mais importante, entre 1808 e 1822, cabe destacar: o Padre Amaro (1820-1826), escrito por Joaquim Ferreira de Freitas; 
O Português (1814-1822) e O Espelho (1813-1814), por Bernardo da Rocha Loureiro; O Campeão (1819-1821), por José Liberato; O Investigador (1811-1819), por José Liberato, José Abrantes e Castro e Vicente Nolasco; e O Correio Braziliense (1808-1822), pelo brasileiro Hipólito José da Costa. Isso para não falar em jornais mais inexpressivos e temporários, como o Argus (1809) e o Zurrague (1821), pelo absolutista José Anselmo Correia, e a Navalha de Figaró (1821), cuja autoria ainda é desconhecida.

É preciso lembrar que esse processo de construção da imprensa lusófona no exterior se dá a partir do contato ativo com a imprensa inglesa e os espaços sociais ingleses disponíveis ao acesso estrangeiro. Frequentemente, os jornais portugueses roubavam temas dos periódicos ingleses, comentavam suas publicações e, no esforço contínuo de rebater as acusações britânicas, acabavam forjando um espaço próprio para a expressão da mentalidade portuguesa e também para o treinamento intelectual dos componentes da imprensa lusófona.

\section{Os portugueses na imprensa inglesa}

Com uma comunidade de leitores escassa, os jornais portugueses publicados no emigrado são todos mensais, com exceção do quinzenal Campeão, surgido às vésperas da Revolução Liberal de 1820, e do diário $O$ Espelho, que sobrevive apenas alguns meses entre 1813 e 1814 . No que diz respeito ao formato, esses jornais se parecem mais com os semanários ingleses, tais como Edinburgh e Quarterly Review, do que com os diários disponibilizados nas tavernas e mencionados por eles à exaustão, em especial The Times e The Morning Chronicle (NUNES; PEREIRA, 1993: 203). Estes dois não apenas são mencionados com frequência como também são procurados por leitores portugueses que almejam tornar públicos os seus comentários a respeito dos importantes acontecimentos em curso entre 1808 e 1822. Mais do que isso, os jornais ingleses tematizam constantemente Brasil e Portugal e ajudam a expandir a rede das sociabilidades portuguesas no estrangeiro. A edição do 
Morning Chronicle de 29 de junho de 1808 noticia, por exemplo, a reunião de mercadores ingleses que buscam negociar com o Brasil. Na mesma edição está a carta de despedida do príncipe D. João aos povos portugueses, ao lado de uma lista de indivíduos que embarcaram para o Brasil. Tanto este jornal quanto ojornal The Times começavam, ao contrário dos incipientes periódicos lusófonos, a investir numa rede de correspondentes para ultrapassar as limitações inerentes às malas postais. Destarte, converteramse, muitas vezes, eles mesmos em fornecedores de panoramas e argumentos para os jornais portugueses. $\mathrm{O}$ pioneirismo no investimento em redes de repórteres coube, segundo Ellis Wasson, ao jornal Morning Chronicle, que

teve, inicialmente, mais cuidado com este processo do que seus concorrentes. Foi o primeiro jornal a usar equipes de repórteres para registrar debates e durante anos a sua cobertura foi considerada superior à do The Times. Seus membros, por vezes, noticiaram que os discursos dos parlamentares whig foram baseados imediatamente no trabalho produzido por eles mesmos (WASSON, 2006: 76. Tradução nossa ${ }^{3}$ ).

A imprensa que se multiplicava em Londres também fazia um amplo trabalho de coleta de jornais estrangeiros, de onde retirava informações. As menções mapeadas vão desde a Gazeta de Moscou até a Gazeta de Buenos Aires. A metalinguagem tornouse entre os jornais ingleses um esforço crítico que permitia aos próprios jornais refletirem os seus padrões impressos e incorporar novas posturas à sua práxis profissional. Desse longo inventário não escapa, evidentemente, a imprensa portuguesa. Quanto aos

\footnotetext{
${ }^{3}$ Do original: "initially paid more care to this process than its competitors. It was the first paper to use teams of reporters to record debates and for years its coverage was considered superior to that of The Times. Its compositors were sometimes given the notes on which whig speeches were based immediately after delivery and worked directly from the".
} 
jornais portugueses no início do século XIX, o Morning Chronicle elencou os seguintes:

O Portuguez Constitucional, O Patriota, O Liberal,

O Mnemosine Constitucional, O Pregoeiro Lusitano,

O Observador Constitucional, impressos em Lisboa, juntamente com outros da Imprensa do Porto, já chegaram até nós, e confessamos que temos lido o seu conteúdo com prazer e espanto. Essa é a principal vantagem que se seguiu à "comoção forte e saudável" em que o português resolveu elevar-se diante de uma degradação que não podia mais ser suportada e promover uma reforma geral em todas as suas preocupações nacionais. Seus progressos neste importante trabalho sempre vão nos proporcionar sincera satisfação (The Morning Chronicle, 13 de novembro de 1820. Tradução nossa ${ }^{4}$ ).

O jornal aponta o estado de relativo desenvolvimento da imprensa em língua portuguesa na entrada dos anos 1820, quando o rompimento da censura surge como consequência da Revolução Liberal do Porto. A extensão da rede de periódicos portugueses utilizados em Londres chega também no Brasil. O jornal Morning Chronicle faz um esforço tão amplo de mapeamento que não deixa nem passar a "Gazeta da Bahia", o jornal Idade d'Ouro (Golden Age) escrito e editado por Diogo de Bivar, referindo-se à capitulação dos revoltosos pernambucanos diante das tropas governistas baianas em 1817:

${ }^{4}$ Do original: "the Portuguez Constitucional, O Patriota, O liberal, O Mnemosine Constitucional, O Pregoeiro Lusitano, O Observador Constitucional, printed in Lisboa, together with others from the Oporto press, have already reached us, and we confess we have noticed their contents with delight and astonishment. Such is the primary advantage that has followed the 'strong and healthful commotion' on which the Portuguese resolved in order to raise themselves from a degradation they could no longer endure, and promote a general reform in the whole of their national concerns. Their further progress in this important work, it will always afford us heartfelt satisfaction to trace". 
Do jornal brasileiro "Idade do Ouro", 30 de maio. Mil parabéns, mil glórias à Bahia e a todos os fiéis súditos de Sua Majestade Fidelíssima, o Rei, nosso Senhor! Mil parabéns, e mil glórias! E por quê? - Porque os soldados da Bahia foram Cipiões reais, não apenas no nome, mas em obras (The Morning Chronicle, 2 de agosto de 1817. Tradução nossa $\left.{ }^{5}\right)$.

O Correio Braziliense, outro coletor exaustivo de documentos e gazetas estrangeiras, também é mencionado pelo Morning Chronicle ao incorporar artigos sobre a educação na Espanha (4 de setembro de 1816). Mais sugestiva, contudo, é a menção a Hipólito da Costa, a única que conseguimos mapear nos extensos anos do Morning Chronicle, curiosamente depois do término de seu periódico. Hippolyto J. Da Costa, "esquire”, é citado como membro do "British commercial life insurance company", situado em Cornhill, "para o seguro de vida e sobrevivência, doações para Crianças, anuidades imediatas ou diferidas, compra e venda de reversões e anuidades, etc. etc" (The Morning Chronicle, 3 de janeiro de 1823, tradução nossa). Pela amplitude da imprensa inglesa no período, é difícil perceber o real trânsito que a comunidade portuguesa tinha em suas páginas. Contudo, algumas indicações sugerem que Hipólito da Costa se tornou uma figura de algum reconhecimento público entre os ingleses. Em 1827, por exemplo, a revista de crítica bibliográfica Quarterly Review comenta o singular caso do Correio:

A publicação de um jornal português em Londres, destinado para a venda no Brasil, onde era proibido, poderia ter parecido apenas uma especulação fadada ao insucesso, mas, no entanto, ele progrediu; e despertou tanto interesse no Brasil e Portugal, que os

${ }^{5}$ Do original: "From the brazilian journal "The Golden Age", may 30. A thousand congratulations, a thousand glories to Bahia, and to all the faithful subjects of his Most Faithful Majesty, the King, our Lord! A thousand congratulations, and a thousand glories! And why? - Because the soldiers of Bahia have been real Scipios, not merely in name but in deed". 
ministros portugueses neste país [Inglaterra] que eram freqüentemente os objetos de ataque lá, consideraram recomendável a criação de um jornal rival em sua própria defesa [O Investigador] (VLI, 1829, 203, apud. REIS, 2007: 69. Tradução nossa $\left.{ }^{6}\right)$.

O esforço de mapeamento presente nos jornais ingleses está vinculado à própria curiosidade iluminista sobre o mundo. A tentativa de catálogo faz parte de registrar o conhecimento desenvolvido por povos de culturas um tanto quanto distantes da inglesa (CLARKE, 2004: 49). A disponibilidade destes jornais ingleses pode também ser considerada como resultado direto da Revolução Gloriosa, que tornou os projetos de liberdade típicos das reivindicações dos philosophes franceses um fator incorporado à própria constitucionalidade britânica (PORTER, 1994: 253). Essa constitucionalidade garantia a liberdade de reunião e trânsito de ideias e forneceu também fundamentos para a construção das sociabilidades intelectuais luso-brasileiras.

Mais do que isso, a organização da esfera pública na Inglaterra caracterizou desde cedo o amadurecimento de uma produção periódica regular destinada às pessoas privadas em detrimento daquela organizada, em última instância, em torno da sociedade de corte. E essa garantia constitucional tornou um imperativo organizacional da política a sua inserção criativa no debate impresso, ainda que, durante um bom tempo, os jornais tenham se negado a entrar decisivamente nas questões governamentais. O envolvimento da imprensa com a vida política se tornará mais comum a partir de meados do século XVIII, quando o lançamento do jornal Morning Post, em 1772, passa a demonstrar como os

\footnotetext{
${ }^{6}$ Do original: "The publication of a Portugueze journal in London, intended for sale in Brazil, where it was sure to be prohibited, might have seemed a rash speculation, which could not possibly succeed, however, it did; and it excited so much interest both in Brazil and Portugal, that the Portugueze ministers in this country, who were frequently the objects of attack there, deemed it advisable to set up a rival journal in their own defence, and with the hope of superseding it".
} 
jornalistas e editores jogavam com políticos e a importância de os ministros terem gazetas favoráveis aos seus posicionamentos ideológicos. A política se constituía e entranhava na vida dos cidadãos através de jornais. Ao mesmo tempo, o Morning Chronicle pode ser considerado pontapé inicial para o desenvolvimento do jornalismo enquanto uma prática profissional enraizada na urbanidade, isto é, como uma forma de escrita regular concernente à organização do espaço público - quando, antes, Addison e Steele e seu Spectator trataram mais decisivamente de organizar o ambiente doméstico e distingui-lo do público.

Aos jornais diários que pulularam em Londres é possível acrescentar as grandes revistas doutrinais do começo do século XIX, Edinburgh Review e Quarterly Review, que ajudaram a dar contornos mais vivos e modernos aos partidos Thory e Whig (COOPER-RICHET, 2006: 413). A produção periódica voltada para temáticas políticas acompanhava a formação de partidos com ideologias razoavelmente bem definidas e cumpria um importante papel no delineamento do Estado Nacional Inglês. Para exemplificar a importância da imprensa nesse processo, vale lembrar que foi a articulação precoce dos setores monárquicos com alas mais progressistas da sociedade que garantiu a permanência do rei enquanto uma figura com papel simbólico importante na Inglaterra (HABERMAS, 2003: 46-7). Sua imagem estava conectada com o próprio conceito da nação inglesa e com a identidade política dos ingleses. E é essa imagem e busca que orientará a "defesa do caráter nacional" empreendida pelos jornalistas luso-brasileiros em Londres. Lentamente, contudo, o rei dos portugueses deixa de ser um taumaturgo e passa a ser revestido de aspectos mais modernos. Ele se torna o "primeiro cidadão" e, dessa forma, também pode ser criticado por atitudes consideradas inconsistentes.

\section{Os portugueses contra a imprensa inglesa}

Se, por um lado, há relativa dificuldade em mapear as referências britânicas à imprensa portuguesa, por outro, as 
impressões que os portugueses têm da imprensa inglesa tornamse muito mais nítidas, até por ela constituir referência e suporte para as publicações portuguesas. $\mathrm{O}$ ar propício para a liberdade de imprensa será visto com bons olhos pelos grupos recém-chegados de portugueses. Tanto nas Cartas a Orestes disponibilizadas no jornal O Português quanto nos longos panegíricos do Correio Braziliense a liberdade inglesa é exaltada e tratada como exemplar para o governo português no Brasil. Ao mesmo tempo, surgem as inevitáveis rusgas entre os panfletistas da causa luso-brasileira com os periódicos ingleses, várias vezes acusados de tratar de forma incompleta os assuntos do Império luso-brasileiro. Sabemos que Hipólito da Costa atua como uma espécie de "observatório da imprensa", criticando uma a uma as produções periódicas que têm como tema o Império. São fartos os exemplos de dissidências existentes entre os portugueses e os ingleses: paira um desconforto diante da submissão de Portugal à Inglaterra, e mesmo diante da ignorância que os ingleses mantêm com relação aos assuntos de Portugal. Loureiro exemplifica bem essa condição quando narra que,

Temos à vista um livro Inglês de geografia elementar, que foi impresso há dois anos: é escrito, como para instrução de meninos, em forma de perguntas e respostas; e quando chega a Portugal, faz-nos o seguinte elogio fúnebre: $\mathrm{P}-\mathrm{Que}$ conceito fazeis vós de Portugal? - R. É a potência mais abjeta da Europa. Valhanos Deus! (O Português, 1814, Vol. I: 35. Grifos no original).

Os portugueses, ao mesmo tempo, sentem-se inseguros diante da avaliação da imprensa inglesa. Ao controle do território português pela armada britânica e aos humilhantes Tratados de Comércio e Navegação de 1810, revela-se o conteúdo depreciativo que pulula nos jornais ingleses, sugerindo a subordinação e inferioridade dos portugueses. Algumas pistas sobre o posicionamento da imprensa inglesa diante dos portugueses recém-chegados são dadas pelo Astro da Lusitânia, em 1821: 
Não ignoramos que os Ingleses [...] de todas as ordens e de todas as classes, têm insultado os Portugueses. Seus jornalistas nos chamam rebanhos de cabras [sic], bandos de ciganos. O autor da História dos Açores (além do intento de persuadir o seu governo que nos empolgasse aquelas Ilhas) depois de nos cobrir de opróbios, acrescentou que nós éramos os homens mais feios do Universo. E Sinval (redator do Astro) acabava por lembrar o célebre verso de Byron sobre o 'Luso escravo', 'dentre os vis o mais vil' (Apud. ALEXANDRE, 1992: 469).

O jornal O Espelho, publicado efemeramente por Rocha Loureiro entre 1813 e 1814, criticou vivamente um panfleto escrito por um "capitão de dragões ligeiros do exército inglês na Península". O dragão ligeiro defendia que, em virtude da incapacidade de os portugueses administrarem seu território, os ingleses deveriam manter a posse dos Açores:

Os portugueses do Continente têm tão más qualidades como estes seus descendentes as têm boas: aqueles são universalmente sem polidez, brutais e ignorantes, feiamente atraiçoados, e cruéis no último ponto, não perdoando nem a seu irmão se a morte deste lhe pode ser útil: seus corpos são magros, mal proporcionados; as feições irregulares e a cor baça: olham para o trabalho como baixo e indigno do homem; e por isso encarregam suas mulheres e escravos de todo trabalho necessário à vida (Apud. O Espelho, n. 6, 1813: 42).

A observação sobre inaptidão dos portugueses ao trabalho lembra, de fato, as características de uma sociedade de Antigo Regime, em cujo cerne os esforços da rotina eram vistos como degradantes. Rocha Loureiro rebate, não sem algum despreparo ao levar ao pé da letra todas as invectivas do "capitão de dragões ligeiros", as suas acusações, defendendo até mesmo a formosura de fisionomia de certos elementos portugueses: 
Também estais enganado, Senhor, na descrição que fazeis das feições, talhe e fisionomia dos portugueses: vós vistes um ou outro português que não mereceu à natureza senão um corpo débil e mal formado; e por aí julgastes da fisionomia dos Portugueses: que errado sistema de avaliar uma nação por indivíduos! Não é assim; os portugueses não têm na verdade os grandes corpos dos alemães; pois são de estatura pela maior parte ordinária; porém em geral são bem fornidos: não têm, como dizeis, as feições contrafeitas e torcidas, e têm regularidade e proporção as partes de seus corpos [...] (O Espelho, V. 1, 1813: 42).

Como acrescenta Fernando Egídio Reis - referindo-se mais especificamente ao jornal Annaes publicado na França sob a direção de Solano Constâncio entre 1815 e 1820 -, era sumamente importante aos portugueses no estrangeiro a modificação da imagem do país no contexto internacional. Os portugueses alegavam a falta de conhecimentos aprofundados dos ingleses sobre o homem português, o que construiria uma falsa imagem de país parado no tempo e tecnologicamente atrasado (REIS, 2007: 289). Destarte, uma real modificação da imagem do país só seria possível através da melhora sistemática da economia e cultura do Reino. Essa situação defensiva, contudo, não impede alguns dos jornalistas portugueses de contra-atacarem, argüindo a incapacidade de os jornais ingleses se afastarem de temas que tocam diretamente suas questões partidárias internas, acabando reféns dos sistemas partidários Tory e Whig. Como argumenta Joaquim Ferreira de Freitas:

Entretanto, os jornalistas ingleses não guardam (como também é justo e natural) a mesma neutralidade e moderação que nós guardamos; porque a questão lhes toca mais de perto, e porque não há questão de que se não aproveitem para ajudar as vistas dos seus diferentes partidos (Padre Amaro, Julho de 1822: 96). 
Aocomentaraênfase dada pelaimprensainglesaà Regeneração Liberal do Porto acontecida em 1820, Joaquim Ferreira de Freitas não a eximiu da crítica por atribuir um falso status de nobreza aos participantes das Cortes de Lisboa, inflando sua importância para além da realidade dos fatos - quer dizer, demonstrando total incapacidade crítica e mesmo puro proselitismo:

Os jornais ingleses têm feito muitas destas graças e ainda não vimos um só rejeitá-las. $\mathrm{O}$ abuso já vem de tempos atrasados: mas por isso mesmo que se fala em reforma de abusos, será preciso reformar este, antes que se veja qualquer dia da presente regeneração, alguma folha liberal dar-nos por aí um conde de José, um Marquês de Fernandez, e um Duque de Thomaz, como já nos deu um conde de Carneiro, e um intrépido redator do Portuguez o Cavaleiro Rocha de Santa Verônica (Padre Amaro, Julho de 1822: 95).

O importante a ser notado é o intenso fluxo discursivo no interior do qual se debate a imprensa emigrada. A difícil questão da definição do espaço nacional passava pelos diálogos com ingleses, brasileiros e espanhóis, todos eles igualmente munidos de órgãos de imprensa em Londres. Mas os homens mais feios do universo dedicariam, em seus jornais, poucas páginas para rebater as acusações que pipocam nos jornais londrinos. Estavam mais ocupados em combaterem uns aos outros e representarem condignamente os indivíduos financiadores que muitas vezes estão enraizados na própria sociedade londrina.

A janela privilegiada para se ter acesso aos diálogos que em geral ocorriam entre os portugueses e os jornais ingleses é o Correio Braziliense, que publicava a íntegra de algumas cartas recebidas pela imprensa londrina e se propunha a refutá-las. Bem como, ao seu tempo, se dispunha a corrigir os "erros crassos" cometidos pela mesma imprensa no que diz respeito à avaliação da situação política do Brasil. Nesse sentido, o jornal The Times publicava uma série de cartas do Braziliano estabelecido em Londres, que se dispunha a, segundo Hipólito, "refutar vários rumores, que 
se têm propagado em algumas gazetas francesas e inglesas, sobre os negócios de Portugal, e entre outros um, de que Sua Majestade havia decretado afinal fixar sua residência no Rio de Janeiro" (Correio Braziliense, Vol. XXIV: 418-9). O papel desempenhado pelo Braziliano é no mínimo inusitado: ele criava a partir dessas cartas um espaço público de discussões sobre os negócios de Portugal no interior dos jornais ingleses. Depois dele surgiram vários escritos de portugueses e brasileiros nas gazetas inglesas, muitos deles com idéias que provocavam calafrios nos adeptos fervorosos de D. João - como, por exemplo, aquelas referentes à união de Portugal com a Espanha para a composição de um único reino. Uma carta anexada no jornal Correio Braziliense acusava o Braziliano, indiretamente, de ser o Conde de Palmela, embaixador português em Londres:

Lembra-se de que foi um dos que teve a baixeza de pedir a Bonaparte um rei. Sabem que foi quem privou os Portugueses do direito impagável que tinham de negociar no tráfico de escravatura ao Norte do Equador; e isto nas suas próprias possessões. Sabem que foi autor do célebre tratado de 22 de Janeiro de 1815 e da convenção adicional de 28 de Julho de 1817, em que se veem entre as muitas passagens, o seguinte, no art. 3 (Apud. Correio Braziliense, Vol XXIV: 647-8).

O jornal Padre Amaro, na mesma direção, refutou o otimismo do Braziliano, dizendo que suas afirmações se encontravam em franca contradição com as mensagens recebidas pelo seu correspondente particular (o ironicamente apelidado "juiz da vintena dos Arcos das Águas Livres de Lisboa"). E culpava o próprio governo pela inexistência de informações verossímeis (sobretudo no que dizia respeito ao retorno ou não do rei para Lisboa). O papel de esclarecer a "opinião pública", então, recai sobre a própria imprensa inglesa (Padre Amaro, V. I, Abril de 1820: 269). Ademais, a revelação de que o Braziliano é na verdade Palmela é bastante inusitada. Em epístola a Thomás Antonio Vila-Nova, Palmela revelou ser o autor das correspondências destinadas ao jornal The Times: 
Remeto incluso a V. Exa. um exemplar do jornal inglês intitulado Times, no qual mandei inserir, debaixo da firma já conhecida de um brasileiro residente em Londres, uma carta que me pareceu nas circunstâncias atuais bastante necessária, a fim de desmentir algumas falsidades que se haviam com malícia evidente feito circular nos periódicos ingleses e franceses, para desassossegar ainda mais os ânimos dos povos de Portugal. Espero que S. M. se dignará aprovar o conteúdo da sobredita carta, que não mandei publicar sem madura meditação, e na qual me parece que me restringi em todos os limites que a prudência exigia (Correspondências e Despachos, 1851: 108).

O Conde de Palmela sofre, nesse contexto, da acusação de ter entregado o Reino na mão de potências estrangeiras em virtude da má habilidade política. Tanto assim que, em 1820, quando ele retorna a Portugal com D. João é impedido de desembarcar pelo "governo revolucionário". Já se alimenta na imprensa londrina, na qual Palmela toma parte, uma figuração negativa do próprio Palmela e vários outros elementos da nobreza portuguesa característica fundamental da formação das esferas públicas. Sabese que desde pelo menos 1814 o conde participa dessa imprensa quando publica no jornal $O$ Investigador fragmentos dos Lusíadas convertidos para o francês. A imprensa torna pública a associação de Palmela com o entreguismo político, num contexto em que qualquer medida que implique na perda da soberania nacional é severamente criticada. A verdade é que o Braziliano Palmela toma parte ativa no comentário desses acontecimentos internacionais de importância e a imprensa emigrada em Londres acaba sendo uma janela privilegiada através da qual podemos perceber como mudanças estruturais no Reino eram vistas e avaliadas pelos portugueses e brasileiros. A atividade do Braziliano foi tão freqüente que, quando finalmente estourou a Revolução do Porto em 1820, o seu silêncio foi logo notado no Correio Braziliense:

As notícias da revolução de Portugal foram publicadas nas gazetas Inglesas com algum estrondo, mas não 
apareceu nenhum parágrafo do Braziliano residente em Londres, nem para as contradizer, nem mesmo para as explicar ou suavizar; pelo que supomos que o tal Braziliano já aqui não reside; ou estará enfermo; se isto é, damos-lhe os pêsames pelas suas moléstias; e lhe recomendamos que incumba alguém a que faça as suas vezes, escrevendo para os jornais Ingleses; por que decerto a revolução em Portugal não é bagatela que se deixe ficar no tinteiro (Correio Braziliense, 1820, Vol XXV: 335).

Os vários diálogos que tinham espaço em jornais londrinos levam-nos a outra conclusão importante: um estadista português escreve para um jornal inglês para publicar as suas idéias e persuadir a opinião dos seus compatriotas num momento decisivo da história de Portugal e Brasil. A opção pelos jornais em língua inglesa podia ser uma medida de precaução: ainda que se dispusesse, entre os emigrados portugueses, de contatos favoráveis, preferia-se a publicação de artigos na imprensa inglesa para evitar associação com um ou outro partido político. Os jornais, nesse momento, aderiam visivelmente a determinadas formas de pensar o Reino luso-brasileiro e os indivíduos que com eles se correspondiam, quando não queriam assumir o estigma de parcialidade, recorriam à imprensa britânica que, aparentemente, nada tinha a ver com o assunto.

O Braziliano, assim, escolheu o jornal The Times para se pronunciar sobre vários assuntos considerados de importância. Ele disse, por exemplo, justificando a sua escolha: “O vosso Jornal goza de tão extensa circulação que tenho julgado ser do meu dever entrar nestas circunstâncias" (apud. Correio Braziliense, Vol. XXIII: 453). Várias vozes dispersas defendiam a soberania portuguesa já que as gazetas inglesas estariam interpretando mal os manifestos portugueses e levando ao ridículo os seus representantes públicos. Hipólito da Costa tentou articular junto aos periódicos ingleses um conjunto de noções que possibilitaram situar aquela terra distante, o Brasil, que aparecia apenas como lugar em guerra ou depósito para a produção industrial inglesa, em uma entidade política 
perceptível para os seus vizinhos londrinos. Empreendeu isso através de uma defesa pública na qual argumentou a soberania do trono português. Trata-se de um "dizer-suporte" que torna o Brasil algo imaginável para os europeus. Hipólito prosseguiu dizendo que "estas gazetas Inglesas e ainda mesmo jornais Portugueses sabem tanto destas matérias como os Bernardos entendem de Lagares de azeite" (Correio Braziliense, Vol. XVIII: 545). Ao mesmo tempo, o jornalista previu as intenções puramente comerciais da Inglaterra junto ao Brasil e alertou: "O motivo que se alega para o Governo Inglês se intrometa nisso não achamos seja o amor da justiça; mas sim o seu comércio no Rio-da-Prata, que dizem chegar a dois milhões esterlinos por ano, empregando também anualmente sessenta vasos" (Correio Braziliense, Vol XVIII: 454).

Ao já citado pioneirismo do Braziliano estabelecido em Londres seguiram-se vários outros escritores portugueses e espanhóis na imprensa em língua inglesa, entre os quais: Philo Justitiae, Averruncus, Veritas, Um Portuguez amante de seu rey e de sua patria. O diálogo se tornou mais intenso quando o primeiro desses escritores defendeu no jornal The Times a posse de Olivença pelos portugueses, tomada pelo Reino Espanhol durante o Congresso de Viena. Tanto portugueses quanto espanhóis, nesse sentido, pareciam não encontrar melhor meio de divulgação de suas ideias a respeito do dissídio do que a imprensa em língua inglesa. Essa etapa dos diálogos se tornou mais particularmente intensa quando Hipólito da Costa criticou a recém-promulgada Constituição Espanhola. Mas, agora, o lugar da argumentação espanhola se deslocava para um importante jornal espanhol: $O$ Espanhol Constitucional. Comentando a escrita de Veritas, também no The Times, Hipólito constatou o que se tornaria um jargão historiográfico, a existência de um "Partido Espanhol em Portugal" que, lutando contra a soberania do Reino Português, defendia a necessidade de sua junção com a Espanha: "quando se considera que Veritas fala quase com autoridade; e certamente como pessoa bem informada dos negócios correntes em Portugal, já se acham bem claras insinuações, de que se está formando um partido 
Espanhol em Portugal, e as insinuações tocam a coisa alta" (Correio Braziliense, Vol. XXI: 210).

Quanto ao Investigador, sua declarada falta de vontade de mexer no ninho de vespas da política lusitana até pelo menos 1814 se tornou, em alguns momentos, caricata: tudo faziam os escritores para manter a subserviência do jornal a D. Domingos e em geral às autoridades portuguesas. Mas também os investigadores rebateram as afirmações dos "gazeteiros ingleses" sobre o estado de degradação de Portugal, reivindicando a "coragem" de suas gentes e a "bravura" de seu exército diante de Napoleão. Havia uma tentativa constante de responder "gazeteiros ingleses" que tratavam com superficialidade a situação portuguesa: "falta [...] nexo aos discursos; e o juízo dos jornalistas são quase sempre temerários" (Investigador, Vol. II: 245). Comentando a obra On the present state of portuguese army, de Andre Halliday, que se refere ao parco papel cabido ao exército português durante a expulsão de Junot, os investigadores observam a negligência do autor quanto ao esforço militar português (Investigador, Vol. II, pp. 190-241). Trata-se, enfim, de defender o celebrado "caráter português" das invectivas da imprensa londrina:

O que nós podemos assegurar [...] é que sem recorrer à citação dos impropérios que continham vários Jornais Ingleses contra as tropas Portuguesas, nós devemos mui particular obrigação ao Exmo. Marechal Beresford pela ânsia que mostrou em aclarar e destruir as calúnias que do mesmo exército se escreveram para a Inglaterra, contra um dos batalhões de Caçadores Portugueses na primeira ação sobre o Coa (Investigador, Vol. II, 1811: 194).

Nas primeiras edições d'O Campeão notou-se também o intercurso com jornais ingleses, ainda que com a singela anexação de algumas cartas publicadas no Times (Campeão, Vol. I, Janeiro de 1820, p. 57). Esse caráter dialógico que a intelectualidade portuguesa manteve com o mundo anglófono ajuda a imaginar a amplitude e os meios ainda irregulares de divulgação de ideias dos 
quais dispunham os portugueses. Quanto a Bernardo da Rocha Loureiro, também não se furta anexar em seu jornal vasto número de documentos traduzidos do Times, entre os quais projetos de cartas constitucionais e documentos sobre a escravatura $(O$ Português, p. 113, p. 239, p. 543).

Percebe-se que as notícias e, depois, os diálogos, envolviam grupos cada vez mais alargados de interlocutores, que lembram, nos debates travados, a idéia de República das Letras. Eles se reuniam para discutir certas diretrizes referentes a várias construções nacionais em curso na Europa e América. Nesse sentido, o cosmopolitismo de Londres favoreceu o florescimento dessa imprensa aberta a discussões de repercussão internacional e os portugueses se movimentavam com liberdade cada vez mais alargada dentro, na maior parte das vezes, do tão propagandeado espírito da polidez, civilidade e reciprocidade iluministas, ainda que com as limitações da mentalidade ibérica.

\section{Considerações Finais}

Diante dos problemas estruturais enfrentados pelo Reino Português no início do século XIX surgiram indivíduos empreendedores ligeiramente desligados do mercantilismo ibérico. Dentre estes indivíduos, podem-se destacar os negociantes Antonio Martins Pedra e Custódio Pereira de Carvalho, acusados de financiarem diretamente escritos periódicos portugueses em Londres, onde buscavam fugir da esfera de ação de Napoleão Bonaparte. A aspiração desses comerciantes por informações e, sobretudo, sua necessidade de militância ideológica contra a situação de abandono do comércio português, pode ser considerada fundamental para a formação de um espaço público que, senão propriamente burguês, é construído a partir do exemplo bem sucedido da imprensa e dos espaços de discussão em Londres.

A necessidade de troca de informações, diante da emergência de um público rudimentar com tinturas liberais, tornou a Londres constitucionalmente livre um palco bastante adequado para a 
atividade intelectual e intercâmbio de informações em língua portuguesa. Para tanto, exerceu influência a imprensa inglesa, que entrava, no começo do século XIX, na era dos grandes periódicos diários, a exemplo do The Times e Morning Chronicle, jornais que tematizavam constantemente Portugal e Brasil. Além desse contato bastante eloqüente com a imprensa inglesa, o intelecto português visitava outros espaços que Habermas situa como componentes da "esfera pública", como os cafés ou tavernas. Sobre as tavernas, é possível dizer a City of London Tavern chegou a se tornar um espaço privilegiado para a entrada de elementos portugueses com ideias liberais, ao mesmo tempo em que afastou a presença de elementos da nobreza, como D. Domingos de Sousa Coutinho (MUNARO, 2013: 2).

Esse contato com o mundo inglês gerou uma série de conflitos de caráter ideológico na medida em que os ingleses argumentavam a incapacidade dos portugueses administrarem o seu próprio território. Através dos intensos debates intelectuais travados, os portugueses e brasileiros construíram uma série de projeções para a sua nação, ajudando, de quebra, a alimentar todo um processo de expressão jornalística em Portugal e Brasil. Como alega Lavina Madeira Ribeiro, sobre o papel "paternal" de Hipólito da Costa diante da esfera pública brasileira,

Sua ação jornalística reveste-se de significativa importância quando observada do ponto de vista da sua contribuição para a formação de um espaço público político brasileiro, com todas as regras e elementos que lhe são particulares e, dentro dele, para a legitimação da imprensa como instituição fundamental deste espaço. O apelo de transparência do Estado perante, seja como ele imaginou, o "povo", a "sociedade em geral" ou segmentos esclarecidos desta, membros do estamento burocrático estatal, sua corte e realeza, deslocava formalmente o campo de legitimação de suas deliberações para o espaço público da sociedade civil, por mais indefinido e basculante que tenha sido o foco conceitual do público imaginado pelo autor. Ao fixar a legitimidade do Estado na "opinião pública", 
Hipólito da Costa consolidava, simultaneamente, o papel e localização da imprensa como instituição imprescindível neste processo (RIBEIRO, 2004: 52).

Hipólito, portanto, através de sua atividade pioneira em Londres, ajudou a fixar um espaço de trocas e interações simbólicas com forte senso crítico diante dos procedimentos estatais. De forma simplificada, pode-se dizer que ele treinou as "elites intelectuais jornalísticas" que se mobilizariam na esteira da independência brasileira, como nos expressivos jornais Revérbero Constitucional Fluminense e O Malagueta que, segundo Hipólito, "nem é destituído de instrução, nem lhe falta o bom raciocínio, e menos a boa linguagem (Vol XXVIII: 453, abril de 1822).

A alimentação dessa imprensa cosmopolita em Londres implica pensar num intenso processo de intercâmbio de ideias relativas à fabricação dos espaços nacionais. Um dos objetivos da imprensa em língua portuguesa é revestir de prestígio a combalida imagem do homem português diante da cada vez mais pejorativa imprensa inglesa. No debate que se trava, Hipólito da Costa e os portugueses são levados também a pensar os pressupostos de funcionamento da imprensa em Portugal e no Brasil, processo que nos permite perceber a importância dos jornais ingleses para o armazenamento e repercussão de temas importantes no Reino luso-brasileiro. O caso do diplomata Palmela, que escrevia constantemente para o The Times para a manifestação de suas preocupações políticas, demonstra como os jornais ingleses estavam presentes no seio dessa esfera pública portuguesa em processo de consolidação.

Enfim, esse fenômeno político que envolve jornais portugueses, brasileiros (a que se chama também, muitas vezes, de portugueses) e ingleses, demonstra como pode ser mais fácil compreender a formação da esfera pública lusófona partindo do papel que a constitucionalidade britânica ali desempenhou. Nesse sentido, pôde-se, no âmbito deste artigo, abrir a porta para uma importante interlocução ainda em processo de desbravamento sobre os suportes da esfera de representatividade pública em 
língua portuguesa, a partir de sua intensa preocupação de reunir os elementos portugueses liberais e garantir que o Estado atuasse em favor dos comerciantes. E, destarte, para a reflexão da própria consolidação de uma modernidade luso-brasileira.

\section{Bibliografia}

ALEXANDRE, V. Os sentidos do Império. Lisboa: Edições Afrontamento, 1993.

ANDERSON, B. Nação e consciência nacional. São Paulo: Ática, 1989.

BRIGGS, A. História Social da Inglaterra. Lisboa: Presença, 1998.

CLARKE, B. From Grub Street to Fleet Street: An Illustrated History of English Newspapers to 1899, Aldershot: Ashgate, 2004.

COOPER-RICHET, D. "As grandes revistas literárias e políticas na formação das elites britânicas durante a primeira metade do século XIX". IN: DUTRA, E. F.; MOLLIER, J.-Y. (orgs.). Política, nação e edição. O lugar dos impressos na construção da vida política. São Paulo: Annablume, 2006.

Correio Braziliense ou Armazém Literário. Hipólito José da Costa. Londres: W. Lewis. 1808-1822.

HABERMAS, J. Mudança estrutural da esfera pública. Rio de Janeiro: Tempo Brasileiro, 2003.

MUNARO, L. F. “Fofocas, boatos e rumores: Do Correio Braziliense ao Padre Amaro em Londres (1808-1822)". Trabalho apresentado no Intercom Manaus - 2013. Disponível em http://portalintercom.org.br/anais/norte2013/resumos/R340135-1.pdf Acesso em Agosto de 2013.

NUNES, M. F.; PEREIRA, S. A. S. M. “O Espírito de Cádiz em O Investigador Português em Inglaterra". IN: Revista Cultura - História e teoria das ideias. No. 7. 1993. p. 197-220. 
O Espelho. Bernardo da Rocha Loureiro. Londres, 1813-1814.

O Investigador Portuguez em Inglaterra ou Jornal Literário, Politico, etc. Bernardo José de Abrantes e Castro, Vicente Pedro Nolasco da Cunha, Miguel Caetano de Castro e José Liberato Freire de Carvalho. Londres, 1811-1819.

O Padre Amaro ou Sovela Politica e Literaria. Joaquim Ferreira de Freitas. Londres, 1820-1828.

O Portuguez ou Mercurio Politico, commercial e litterario. João Bernardo da Rocha Loureiro. Londres, 1814-1822.

PORTER, R. "Enlightenment London and Urbanity". IN: HEMMING, T. D.; MEAKIN, D. The Secular City: Studies in the Enlightenment. Exeter: Univeristy of Exeter, 1994.

REIS, F. E. Os Periódicos portugueses de emigração (1808-1822). As ciências e a transformação do país. Tese de doutorado apresentada à Universidade Nova de Lisboa, 2007.

RIBEIRO, L. M. Imprensa e espaço público. A institucionalização do Jornalismo no Brasil (1808-1964). E-papers, 2004.

The Morning Chronicle. Londres, 1808-1822.

VASCONCELLOS, J. J. R. Despachos e correspondência do Duque de Palmela. Lisboa: Imprensa Nacional, 1851.

WASSON, E. A. "The Whigs and the press, 1800-50". Parliamentary History, v. 25, Part 1, 2006, p. 68-87.

Recebido em 02/09/2013.

Aprovado em 13/05/2014. 
